\title{
AN ELECTROSPUN POLYDIOXANONE PATCH FOR THE LOCALISATION OF BIOLOGICAL THERAPIES DURING TENDON REPAIR
}

\author{
O. Hakimi ${ }^{1}$,* R. Murphy ${ }^{1}$, U. Stachewicz ${ }^{2}$, S. Hislop ${ }^{1}$ and A.J. Carr ${ }^{1}$ \\ 'NIHR Biomedical Research Unit, Nuffield Department of Orthopaedics, \\ Rheumatology and Musculoskeletal Sciences, University of Oxford, Oxford, UK \\ ${ }^{2}$ Nanoforce Technology Ltd., Queen Mary University of London, Mile End Road, London E1 4NS, UK
}

\begin{abstract}
Rotator cuff tendon pathology is thought to account for $30-70 \%$ of all shoulder pain. For cases that have failed conservative treatment, surgical re-attachment of the tendon to the bone with a non-absorbable suture is a common option. However, the failure rate of these repairs is high, estimated at up to $75 \%$. Studies have shown that in late disease stages the tendon itself is extremely degenerate, with reduced cell numbers and poor matrix organisation. Thus, it has been suggested that adding biological factors such as platelet rich plasma (PRP) and mesenchymal stem cells could improve healing. However, the articular capsule of the glenohumeral joint and the subacromial bursa are large spaces, and injecting beneficial factors into these sites does not ensure localisation to the area of tendon damage.

Thus, the aim of this study was to develop a biocompatible patch for improving the healing rates of rotator cuff repairs. The patch will create a confinement around the repair area and will be used to guide injections to the vicinity of the surgical repair.

Here, we characterised and tested a preliminary prototype of the patch utilising in vitro tools and primary tendon-derived cells, showing exceptional biocompatibility despite rapid degradation, improved cell attachment and that cells could migrate across the patch towards a chemoattractant. Finally, we showed the feasibility of detecting the patch using ultrasound and injecting liquid into the confinement ex vivo. There is a potential for using this scaffold in the surgical repair of interfaces such as the tendon insertion in the rotator cuff, in conjunction with beneficial factors.
\end{abstract}

Keywords: Polydioxanone; tendon; biocompatibility; degradation; cell viability; cell adhesion.

*Address for correspondence:

O. Hakimi

NIHR Biomedical Research Unit

Nuffield Department of Orthopaedics, Rheumatology and Musculoskeletal Sciences University of Oxford,

Oxford, UK

E-mail: osnat.hakimi@ndorms.ox.ac.uk

\section{Introduction}

Rotator cuff tendon pathology is thought to account for 30-70 \% of all shoulder pain (Urwin et al., 1998; Bongers, 2001). For cases that have failed conservative treatment, a simple surgical re-attachment of the tendon to the bone with a non-absorbable suture is the most common option. However, the failure rate of these repairs is very high, estimated at up to $75 \%$ (Galatz et al., 2004; Bishop et al., 2006; Huijsmans et al., 2007; Sugaya et al., 2007). A number of studies have shown that in late disease stages the tendon itself is extremely degenerate, with reduced cell numbers and poor matrix organisation (Cole et al., 2001; Benson et al., 2009).

Whilst a large volume of research has been concerned with improving the strength of the augmentation (Kimura et al., 2003; Muller et al., 2003; Audenaert et al., 2006; Ammon et al., 2007; Derwin et al., 2009; Fang et al., 2009), one study has shown that the reason for failing repairs is poor tissue quality rather than the suture strength (Cummins and Murrell, 2003). Indeed, recent work has emphasised the importance of the biological environment and the tissue's capacity to heal ( Kajikawa et al., 2008; Derwin et al., 2010).

Research centred on the biology of tendon repair has given rise to a second generation of implants composed of matrix proteins such as collagen, expected to encourage neo-tendon formation by providing an appropriate scaffold (Derwin et al., 2006; Fini et al., 2007). However, these implants are costly, and being xenografts or allografts may carry the risk of pathogen transfer. Moreover, their efficacy has not been fully proven.

The latest generation of therapies has been concerned with targeting the cell populations in the torn tendon by using biological stimulation such as growth factors (Costa et al., 2006; Rodeo, 2007). For example, some newly developed treatments utilise platelet rich plasma (PRP) as a source of growth factors (De Mos et al., 2008; Maniscalco et al., 2008; McCarrel and Fortier, 2009; Silva and Sampaio, 2009) or autologous mesenchymal stem cells as mediators of tendon repair (Awad et al., 1999; Butler et al., 2008; Chong et al., 2007). Many of these novel therapies have been based on the use of a degradable scaffold to release the 'biological enhancers' (Awad et al., 1999; Chong et al., 2007). Others propose to inject them into the joint capsule without any localisation or load them into the sutures used for the repair (Hamada et al., 2006; Rohrich et al., 1999).

In this study, we propose to improve healing by localising various biologically active substances above the 
tendon tear during surgical rotator cuff repair. The gradual release of a bio-active component from a degradable scaffold has already been suggested (Cushnie et al., 2010), but here we outline a novel approach of creating a temporary confinement above the repair that can contain injected factors such as PRP, growth factors or cells. Such a confinement will be created by suturing a degradable patch above the double-row repair of the tendon to the bone, thus allowing the re-injection of beneficial factors post-operatively and a continuous biological stimulation of the tissue. Unlike traditional tissue engineered scaffolds, designed to be replaced by a viable neo-tissue, the confinement patch will act as a shorter-term 'healing booster' for the critical repair window of 1-8 weeks after surgery, and is not required to stay intact thereafter.

Moreover, in the case of the human rotator cuff it is often the case that complete and watertight approximation of the tendon to bone is not possible at the time of surgery. Gap formation may also occur in the first days and weeks after repair in response to tensile loading. These factors allow the synovial environment of the joint and the subacromial bursa to adversely influence healing and account, in part, for the high rates of failure currently observed in clinical trials (Lorbach and Tompkins, 2012; Shea et al., 2012). The role of the patch will therefore also be to provide a protective environment on the superior surface of this complex repair site in order to encourage a more successful healing response. The patch does not directly interpose between tendon and bone, as this runs the risk of adversely influencing tendon to bone healing as a consequence of cells from both sides of the repair migrating, proliferating and differentiating.

For this "proof of concept" study, four major aspects of the patch were considered: (1) Handling properties, (2) Degradation rate, (3) Biocompatibility and (4) Cell attachment and migration. These aspects are discussed below.

\section{Handling properties}

PDO sutures and sheets are considered stiff and difficult to handle, and it is thought that as a result scar tissue formed around them is weak (Baumann et al., 2002). It has been reported that perforated PDO foil has performed better because it allowed adequate blood supply (Tweedie et al., 2010). Thus, it was desirable to construct a PDO scaffold that would be easier to handle but also allow good vascularisation.

Previous reported work has shown that it is feasible to produce thin PDO fibres of diameters ranging between 0.18-1.4 $\mu \mathrm{m}$ by electrospinning (Boland et al., 2005) and that the resulting material is a good scaffold for hard tissue engineering (Kalfa et al., 2010). Here, we produced preliminary prototypes of the confinement patch from electrospun polydioxanone and as a comparison, the commercial dura-patch Ethisorb was used, as it contains a PDO sheet.

\section{Degradation rate}

The rapid degradation of the patch was of particular importance in its design for three reasons; a) avoiding the extensive granulation tissue and fibrous capsule formed around non-degrading and slow-degrading implants; b) allowing a timely release of beneficial factors during the critical repair period of 1-8 weeks post-surgery; and c) minimising the period of acidic degradation products release, which can alter healing as well as effect angiogenesis (Martin et al., 1996; Mikos et al., 1998).

It has been reported that PDO sheets were well tolerated with minimal foreign body reaction despite rapid degradation and particles detaching from the surface of the sheet (Kontio et al., 2005). However, the effect of accelerated degradation and the leeching of the acidic degradation products associated with $\alpha$-hydroxy acids on cell viability has not been previously reported.

\section{Biocompatibility and cell attachment and migration}

Minimal tissue reaction and good ability to contain cells and fluids were the preliminary requisites when selecting a material for the creation of the patch. In a previous study, we have highlighted polydioxanone (PDO) as a candidate material for tendon repair because it was particularly compatible with tendon-derived cells in vitro (Hakimi et al., 2012). Moreover, it has an excellent history as an implant material even at large quantities of material, with acceptable host response and no severe inflammation (Curtis et al., 2005). However, despite excellent biocompatibility, PDO sutures (PDSII) displayed relatively low cell attachment in vitro (Hakimi et al., 2012). One challenge was therefore to design a PDO-based scaffold that will retain its biocompatibility but encourage cell attachment.

\section{Aim}

The aim of this study was to develop a highly biocompatible patch for improving the healing rates of rotator cuff repairs. The patch will create a confinement around the repair area and will be used to guide injections to the vicinity of the surgical repair. The patch will be mechanically sound for the critical regenerative period following rotator cuff repair but will rapidly degrade thereafter. It will produce minimal immune response and be able to retain and deliver cells and beneficial factors to the healing tendon. The results presented here represent the preliminary "proof of concept" stage in the development of the patch.

\section{Materials and Methods}

\section{Polydioxanone patch prototype}

Poly(dioxanone) (PDO, Sigma-Aldrich, Gillingham, Dorset, UK) was dissolved in 1,1,1,3,3,3-Hexafluoro2-propanol (HFP, Fluka Analytical/Sigma-Aldrich) to produce a polymer concentration of $7 \% \mathrm{wt}$ in solution. This concentration was chosen after an optimisation process to adjust the viscosity of the solution for electrospinning. Solution viscosity and the resulting fibre diameter increase with increased concentration. Lower concentrations (such as $5 \%$ ) produced fibres that were non-uniform. $7 \%$ wt. was the optimum concentration to produce uniform but thin electrospun fibres using the set up described here.

PDO fibres were electrospun from a single nozzle setup at voltage of $13.5 \mathrm{kV}$ (Glassman, Bramley, Hampshire, 


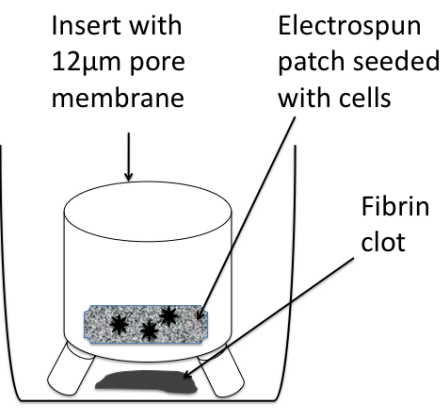

b

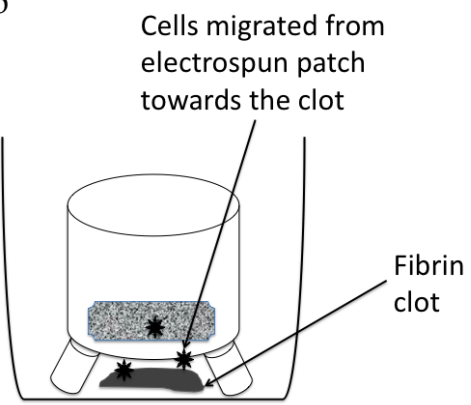

c Insert removed to allow quantification of cell numbers

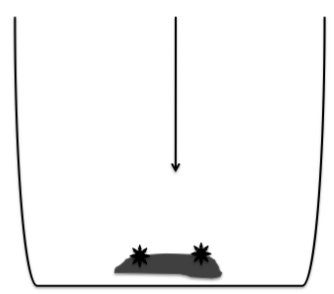

Fig. 1. A schematic representation of the migration assay, showing the exposure of the cell-seeded patch to the fibrin clot (a), the migration across a $12 \mu \mathrm{m}$ pored membrane (b) and quantification of migrated cell by alamarBlue (c).

UK) and a distance of $26.5 \mathrm{~cm}$ between the nozzle and the grounded electrode. The polymer solution was supplied with a syringe pump (Harvard Apparatus-PHD 2000, Kent, UK) at a flow rate of $1 \mathrm{~mL} / \mathrm{h}$. The applied voltage at the metal needle caused charge build-up at the polymer solution meniscus hanging at the end of a nozzle until cone-jet formation and stretching jets towards the ground electrode occurred and solid nanofibres were deposited on aluminium foil. The rate of production for a patch was approximately $2 \mathrm{~cm}^{2} / \mathrm{h}$, resulting in an average thickness of 0.2-0.4 mm. Thick areas of the patch could be easily peeled from the aluminium foil, however to remove thinner sections of electrospun patches, the sample was bathed in $70 \%$ ethanol and gently scraped from the foil using forceps. $70 \%$ ethanol was used as it helps remove residue water as well as sterilise the sample. As shown in Fig. 2, the electrospun PDO fibre diameter, measured using scanning electron microscopy (SEM) (Inspect F, FEI Company, Hillsboro, OR, USA), was between 0.1 and $1 \mu \mathrm{m}$. The density of electrospun patches was measured using a gas pycnometer (AccuPyc $1330 \mathrm{He}$, Micromeretics, Norcross, GA, USA).

\section{Control materials}

Three different controls have been utilised:

1. Ethisorb (DuraPatch, DePuy, Raynham, MA, USA), implant used to repair Dura matter, and comprises of a Vicryl fleece (Polyglactin 910) and a PDO foil dyed with D\&C Violet. Ethisorb was used as a control for in vitro cell experiments, which require a continuous surface for cell expansion.

2. PDSII sutures (Ethicon, Johnson and Johnson Medical, Livingston, West Lothian, UK) were used as control for weight loss and indirect exposure experiments, as it is made from polydioxanone only and provides a chemically identical control.

3. Glass cover slips (Fisher, Loughborough, UK) or tissue culture (TC) plastic were used as a non-material control for in vitro cell experiments.

\section{Degradation}

To assess degradation, patches and sutures of known weight were sterilised using $70 \%$ extra pure ethanol (Sigma-Aldrich) for at least one hour and covered in sterile phosphate buffered saline ( $\mathrm{x} 1$ phosphate buffered saline (PBS), Invitrogen/Life Technologies, Paisley, UK) at a ratio of approximately $1 \mathrm{mg}$ material in $1 \mathrm{~mL}$ PBS. At each time point, samples were dried at $60^{\circ} \mathrm{C}$ overnight and weighed in an AE200 Mettler (www.mt.com) balance. To image the effect of the degradation process, patches, either fresh or incubated in sterile PBS for 8 weeks were mounted on aluminium stubs and gold sputtered. Patches were examined in a Zeiss (Oberkochen, Germany) Evo LS15 variable pressure scanning electron microscope.

\section{Human tendon material, donor demographics and clinical data}

Tendon tissue was obtained from the Oxford Musculoskeletal Biobank, with informed donor consent in full compliance with the National and Institutional ethical requirements, the United Kingdom Human Tissue Act (HTA).

Supraspinatus tendon samples were collected from patients with chronic degenerative rotator cuff tendinopathy and partial/full thickness supraspinatus tears. All patients were undergoing surgery for rotator cuff repair or subacromial decompression, during which tendon tissue was resected from the distal torn edge of the tendon and transferred immediately into a sterile tube containing DMEM F12 (Lonza, Slough, UK) for explantation. Tendon-derived cells for this study were obtained from 5 male and 1 female donors aged 48-72 years (mean age 57.3 years). Cells from each donor were used individually.

\section{Tendon-derived cell isolation and culture}

The tendon samples were cut into small uniform pieces under sterile conditions and transferred to 6-well plates (Corning, Corning, NY, USA) supplemented with growth medium. Growth medium used was DMEM F12 containing $50 \%$ foetal bovine serum (FBS, Biosera Ringmer, East Sussex, UK) and $1 \%$ penicillin-streptomycin solution. Plates were incubated at standard conditions $\left(37^{\circ} \mathrm{C}\right.$, $5 \% \mathrm{CO}_{2}$ ) and growth medium was replaced every 2-3 days. Once cells had migrated from the explants, after approximately 7 days, the medium was refreshed with DMEM F12 containing $10 \%$ FBS. Cultures were maintained under these conditions until the wells reached confluence. The cells were then scraped and sub-cultured under the same conditions in $10 \mathrm{~cm}$ Petri dishes (Greiner, Frickenhausen, Germany) to allow proliferation. For all experiments, for consistency, and to avoid the phenotypic drift described after passage 5 (Yao et al., 2006; Poulsen 
et al., 2011), tendon derived cells were used in the second passage.

\section{Cell growth on the patches}

To assess growth on the electrospun patches, an alamarBlue ${ }^{\circledR}$ assay was used as previously described (Hakimi et al., 2012). Briefly, tendon-derived cells were seeded into 24-well plates (Corning) containing electrospun patches and allowed to attach for at least $12 \mathrm{~h}$. At selected time points, the patches were transferred into fresh well plates containing complete medium with $5 \%$ alamarBlue ${ }^{\circledR}$ (AbD Serotec, Oxford, UK). Patches were transferred into fresh wells in every time point in order to exclude cells attached to the polystyrene well and measure exclusively the metabolism of cells attached to the patch.

After $2 \mathrm{~h}$ of incubation, duplicates of $100 \mu \mathrm{L}$ medium samples from each well were transferred to 96-well plates (Corning) for analysis in a SpectraMax Gemini microplate reader (Molecular Devices, Winnersh, Berkshire, UK), with fluorescence measured at $544 \mathrm{~nm}$ excitation and $590 \mathrm{~nm}$ emission wavelength. The remaining alamarBlue ${ }^{\circledR}$ medium was removed and replaced with fresh standard medium.

\section{Effect of conditioned media on cell growth}

To condition the medium, each prototype at a concentration of $20 \mathrm{mg} / \mathrm{mL}$ was incubated for 8 weeks in DMEM-F12 at $37{ }^{\circ} \mathrm{C}, 5 \% \mathrm{CO}_{2}$. At each time point (weeks 1, 3, 4, 5,6 and 8 ), $2 \times 10^{4}$ cells were seeded into 96-well plates in quadruplets and their viability before exposure was assessed at day 1 by alamarBlue ${ }^{\circledR}$, as described above. Immediately after, $1 \mathrm{~mL}$ of the patch-conditioned medium was supplemented with $10 \%$ FCS and fed to cells grown in 96-well plates. Proliferation was measured after $48 \mathrm{~h}$ of exposure, calculated as relative to day 1 , and normalised to the control (no material) group.

\section{Effect of poly( $\alpha$-hydroxy) acids on cell growth}

It was of interest to measure the effect of poly-( $\alpha$-hydroxy) acids on cell growth, as these acids are the final degradation products of the polymers used in this study (polydioxanone and polyglactin 910). Thus, DMEM growth medium was supplemented with concentrations between $1 \mu \mathrm{M}-1 \mathrm{M}$ of lactate, glyoxylic acid and glycolic acid (all from SigmaAldrich). Growth medium was sterilised by filtration and supplemented with $5 \% \mathrm{v} / \mathrm{v}$ FBS. $2 \times 10^{4}$ cells/well were seeded into 96-well plates in quadruplets and their viability before exposure was assessed at day 1 by alamarBlue ${ }^{\circledR}$, as described above. Immediately after, the supplemented media was fed to the cells. Proliferation was measured after $48 \mathrm{~h}$ of exposure and calculated as relative to day 1 .

\section{Visualisation of cell attachment to different polydioxanone constructions}

To compare the attachment and spreading of tendon derived cells, four different substrates have been used: tissue culture plastic, PDSII sutures woven into a mat as previously described (Hakimi et al., 2012), a PDO drop prepared by autoclaving PDSII suture fragments on glass slides in order to melt and re-form the polymer as a uniform polydioxanone drop, and the electrospun
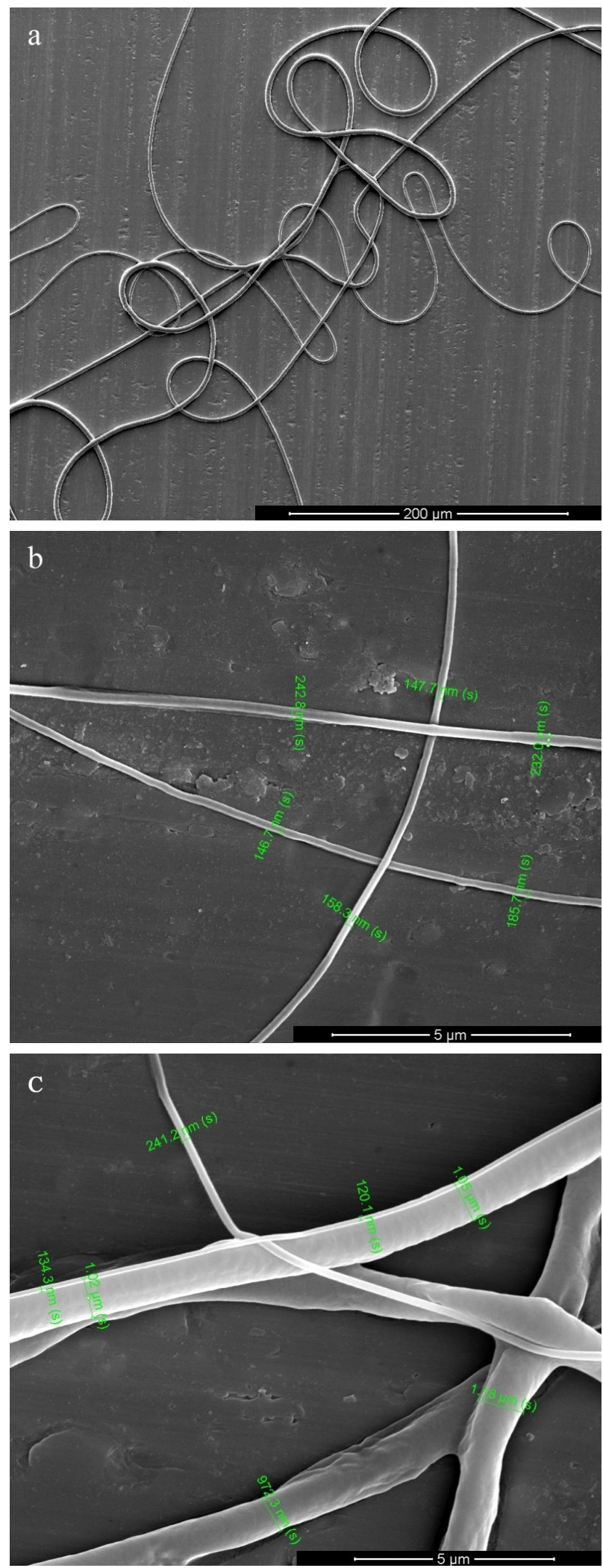

Fig. 2. Electron micrographs showing randomly oriented electrospun polydioxanone fibres (a) and the variation in fibre diameter $(\mathbf{b}, \mathbf{c})$.

patch. All substrates were sterilised with $70 \%$ ethanol for at least $1 \mathrm{~h}$ and then washed twice with DMEM-F12. Cells at a concentration of $10^{5}$ cells $/ \mathrm{mL}$ were seeded onto the materials and allowed to grow for at least 7 days at standard conditions. This cell number was chosen based on previous cell growth assays with scaffolds of similar size, 
Fig. 3. Weight loss of polydioxanone in PBS over 200 days. After 50 days, the electrospun patches lost their integrity and thus weight could not be assessed, whilst sutures retained over $75 \%$ of their weight $(n=3)$.

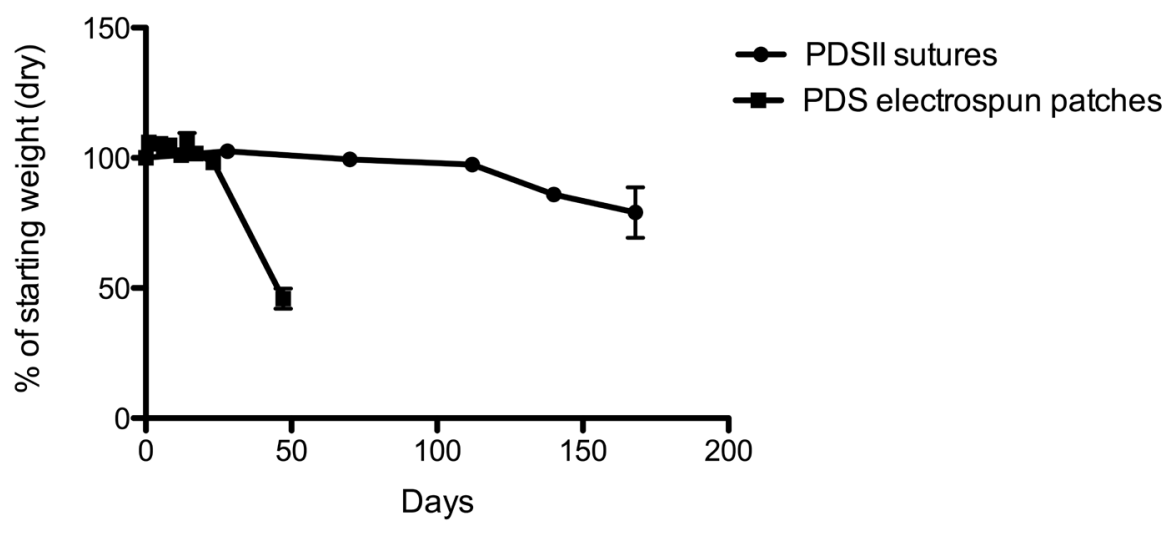

and taking into account a fraction of cells attaching to the tissue plastic around the scaffold (Hakimi et al., 2012). To visualise the cells, constructs were fixed in $10 \%$ formalin (Fisher Scientific, Loughborough, UK) for $5 \mathrm{~min}$ and permeabilised using $0.1 \%$ Triton-X (Sigma-Aldrich) for 5 min. Consequently, cells were stained using Rhodamine Phalloidin (Invitrogen/Life Technologies) and DAPI nuclear counter stain (4',6-diamidino-2-phenylindole) according to manufacturer's instructions (Molecular Probes/Life Technologies). Samples were visualised using a fluorescence microscope (BX40, Olympus or eclipse TE300, Nikon, Tokyo, Japan).

\section{Cell migration from the patch}

In order to measure the ability of the patch to release cells, a migration study was set up using a well plate insert (12 $\mu \mathrm{m}$ pores, 24-well inserts, Millipore, Carrigtwohill, County Cork, Ireland), as shown schematically in Fig. 1. Approximately $5 \times 10^{4}$ cells were seeded either directly onto the insert membrane or onto an electrospun patch that was later transferred into an insert. A 24-well plate (Corning) was coated with fibrin gel, prepared from $100 \mu \mathrm{L}$ of $10 \mathrm{mg} / \mathrm{mL}$ fibrinogen and $2 \mu \mathrm{L}$ of $100 \mathrm{U} / \mathrm{mL}$ thrombin from bovine plasma (both Sigma-Aldrich), acting as a chemo-attractant. The inserts were then transferred into the wells containing the fibrin, covered in growth medium and incubated for $48 \mathrm{~h}$. Thereafter, an alamarBlue ${ }^{\circledR}$ assay was carried out as described above to measure cell growth above and below the insert, thus determining the extent of migration across the membrane.

\section{Ultrasound simulation}

To simulate the in vivo imaging environment, a $1 \mathrm{~cm}$ square electrospun patch was attached to a sample of sheep infraspinatus tendon and embedded within a gelatin-based phantom model. This model is routinely used for teaching and training clinicians in ultrasound guided injection techniques. The patch was imaged using a GE Healthcare (www.ge.com) Logiq E9 with $13 \mathrm{MHz}$ linear array probe.

\section{Sham operation}

In order to test the efficacy of the patch as a confinement device, a sham operation and injection was carried out in a cadaveric sheep shoulder. First, a defect was introduced into the infraspinatus tendon by detaching it from the greater tuberosity of the humerus. Second, a double row rotator cuff repair was carried out using 2 titanium screwin anchors for the medial row and two knotless push-in anchors for the lateral row of the repair. The suture material used to repair the tendon was Fibrewire gauge 2-0 (Arthrex, Sheffield, UK). A patch of roughly $3 \mathrm{~cm}$ diameter was then sutured above the repair. The patch was imaged using ultrasound as described above and two guided injections of different coloured ink were undertaken. Guided injection of ink into the patch was performed using a $2 \mathrm{~mL}$ syringe and a 23-gauge needle (Terumo, Egham, Surrey, UK). Ink was used simply to confirm the accuracy of the injection and the ability of the patch to contain the injected fluid.

\section{Experimental design and statistical analysis}

All experiments with cells were repeated at least twice using a different donor for each experiment. To ensure repeats are comparable, each experiment had a non-treated control from the same donor, and wherever possible results were normalised, either to control (Fig. 6) or to the starting point of the experiment (Figs. 5, 7 and 9).

Results were analysed by one-way ANOVA test with a post hoc Newman-Keuls multiple comparison (Figs. 5 and 6) or by Student's $t$-test (Fig. 9) using Prism version 5 (Graphpad, San Diego, CA, USA). Results are expressed as mean \pm SEM and $p$ values were annotated on the graph as follows: ${ }^{*} p \leq 0.05, * * p \leq 0.01$ and $* * * p \leq 0.001$.

\section{Results}

\section{Patch characterisation: fibre appearance, diameter and degradation}

As can be seen in Fig. 2, the electrospun patch was composed of randomly oriented fibres with smooth surfaces and variable diameters. The average diameter was $582 \pm 483 \mathrm{~nm}(n=16)$, and the average density was $1.124 \mathrm{~g} /$ $\mathrm{cm}^{3}$. Moreover, the patch was heterogeneous, with areas of compact dense fibres and others more open. Degradation was significantly more rapid in the electrospun patches compared with the commercially available PDSII sutures, and the patch lost approximately $50 \%$ of its dry weight after fifty days of incubation in PBS (Fig. 3). Moreover, as can be seen in Fig. 4, after eight weeks in PBS, degraded patches presented an altered morphology of short fibre fragments densely packed together. 

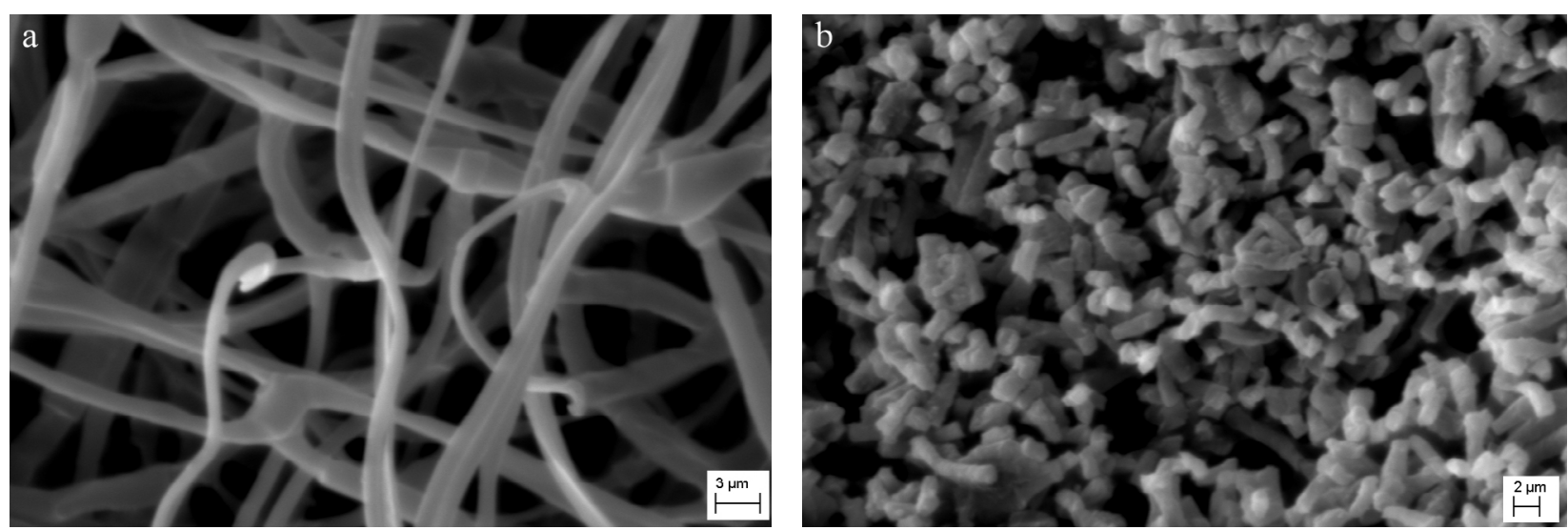

Fig. 4. SEM images showing the appearance of the electrospun patch before (a) and after (b) incubation in PBS for 8 weeks.

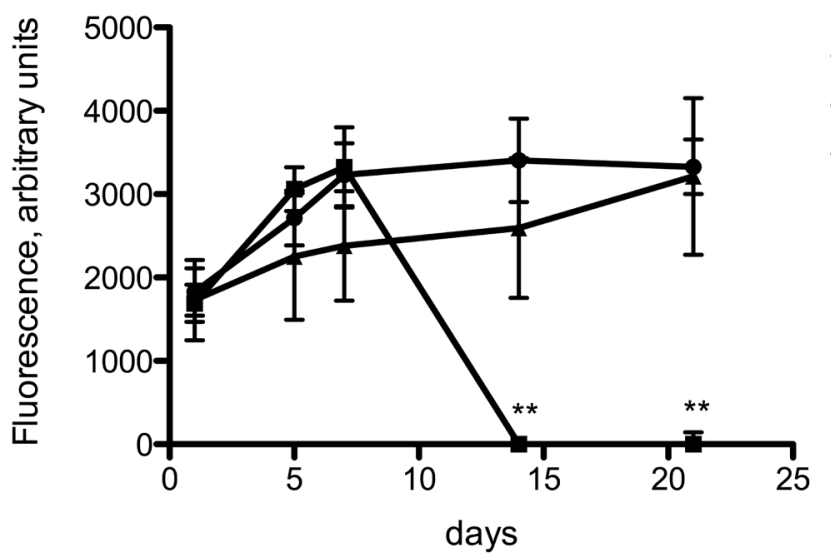

Fig.5. Cell proliferation on the electrospun polydioxanone patch over 21 days compared to tissue culture plastic and Ethisorb. Cell growth was measured using alamarBlue $(n>4)$. Only cells grown on Ethisorb showed a statistically significant difference in proliferation rates (Day $14 p=0.0057$, Day $21 p=0.0016$ ).

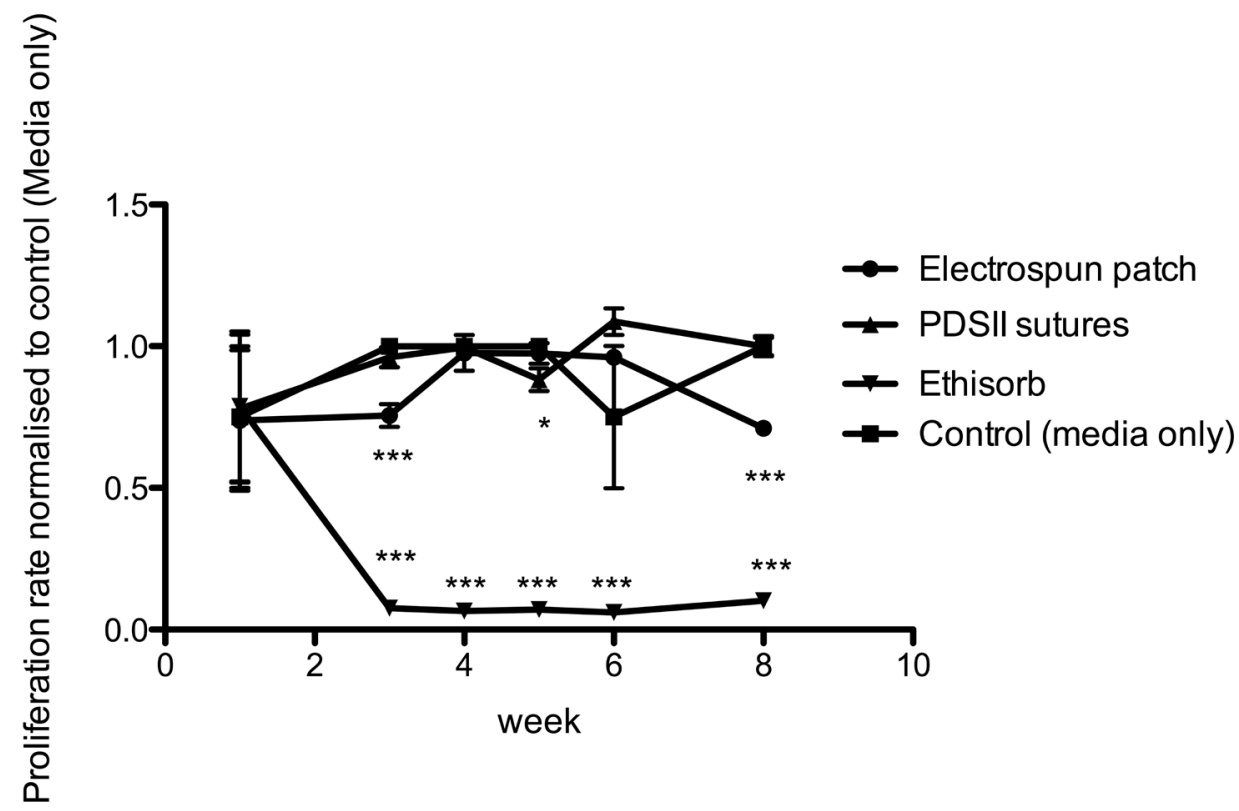

Fig. 6. The effect of media conditioned for 8 weeks with the electrospun polydioxanone patch, PDSII sutures and Ethisorb on cell growth $(n=4) .20 \mathrm{mg}$ of each material was incubated in $1 \mathrm{~mL}$ media. Cell growth was normalised to a no-material control. On week 1 there was no statistical difference between cells exposed to the different materials. Cells grown in Ethisrob-conditioned media had a statistically different growth rate from all other groups for all time points $(p<0.001)$. At week 3 and 8 cells grown in media conditioned with the electrospun patch showed a slight but statistically significant reduction in growth rate $(p<0.001)$, but not at other time points. At week 5 cells grown in media conditioned with PDSII sutures showed a small but statistically significant reduction in growth rate $(p<0.05)$, but not at any other time point. 
Fig. 7. The effect of glyoxylic, lactic and glycolic acid on cell growth over $48 \mathrm{~h}$ in culture $(n=4)$.

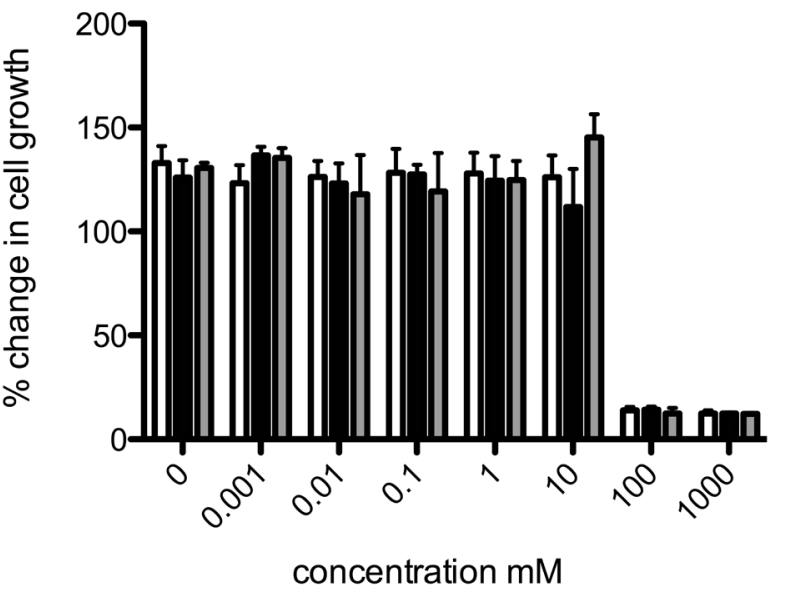

concentration mM

Table 1. The maximal concentration $(\mathrm{mM})$ of the degradation products in the conditioned media.

\begin{tabular}{|c|c|c|c|}
\hline Weight/Volume $\quad$ Degradation product & Glyoxylic acid & Lactic acid & Glycolic acid \\
\hline $20 \mathrm{mg} / \mathrm{mL}$ & $270 \mathrm{mM}$ & $222 \mathrm{mM}$ & $263 \mathrm{mM}$ \\
\hline
\end{tabular}

\section{Biocompatibility of the electrospun patch and its degradation products}

It was of interest to measure the effect of the patch, both intact and degraded, on cell populations from the rotator cuff. This was to ensure the safety of the patch over its lifetime as an implant, but also in order test the feasibility of using the patch to capture and deliver cells, PRP, or any other beneficial supplement. As can be seen in Fig. 5, cells attached to all tested materials (Electrospun patch, Ethisorb and tissue culture plastic). Cells survived on the electrospun patch for at least 21 days, and the rate of metabolism was similar to that of cells grown on tissue culture plastic. Cells stopped proliferating on the Ethisorb implant after 7 days.

Cells were also grown in media exposed to these materials for up to 12 weeks. The media exposed to the materials was only refreshed at each time point, thus showing the effect of degradation products accumulated over 1-2 weeks. All materials were conditioned at approximately $20 \mathrm{mg}$ material per $1 \mathrm{~mL}$ media. As can be seen in Fig. 6, media exposed to the electrospun patch had little effect on cell growth until week 6, when a detectable reduction in cell growth compared to control is apparent. PDSII sutures had little or no effect on cell growth. The Ethisorb patch had a strong negative effect on cell growth from as early as week 3 , almost completely inhibiting cell growth.

Fig. 7 shows the short-term effect of the degradation products of PDO (glyoxylic acid) as well as Ethisorb (glycolic acid, lactic acid and glyoxylic acid) on cell growth. The results show that all these poly-( $\alpha$-hydroxy) acids had a similar effect on cell growth, with a strong cell growth inhibition at high concentration (1 M and $100 \mathrm{mM}$ ) but not at $10 \mathrm{mM}$ or lower concentrations.

The calculated maximal acid concentration in a medium conditioned with a material at the dry weight of $20 \mathrm{mg}$ material per $1 \mathrm{~mL}$ of media is shown in Table
1. This demonstrates the likely possibility that at a high degradation rate or insufficient circulation, the acidic products could reach toxic levels.

\section{Efficacy of the patch as a cell substrate in vitro}

The patch was needed in order to create a confinement for stem cells or other beneficial factors. Thus, it was of interest to select a material construction that would maximise cell attachment and delivery. Figure 8 shows the spreading and morphology of tendon derived cells on different constructions of PDO. The images clearly demonstrate that cells attached very well to tissue culture plastic and created a continuous monolayer (Fig. 8A,B). Cells barely attached to the PDO drop, despite attaching very well to the glass surface around it (Fig. 8C,D). The polydioxanone suture (PDSII) showed some cell attachment, but this was inconsistent and often included cell clumps "trapped" between monofilaments (Fig. 8E,F). Cells seeded on the electrospun patch attached very well throughout the patch, with no visible clumps of cells. Cells appeared elongated along the spun fibres whilst forming numerous cell-cell contacts. Micrographs also confirmed good coverage of the patch with cells even at final time points of the alamarBlue ${ }^{\circledR}$ assay, after the patch was moved several times into fresh wells. Overall, the electrospun construction appeared favourable as a cell substrate.

As was demonstrated in Fig. 5, cells also grew on the patch for a period of up to 21 days in rates equivalent to growth on tissue culture plastic. However, it was necessary to measure the ability to induce cell migration from the patch towards a different surface, in order to ensure that cells delivered into the patch can migrate out to the region of repair. To do that, a patch seeded with tendon-derived cells was placed on a porous membrane and a fibrin clot on the other side of the membrane acted as a chemoattractant (see a schematic diagram in Fig. 1). As can be 


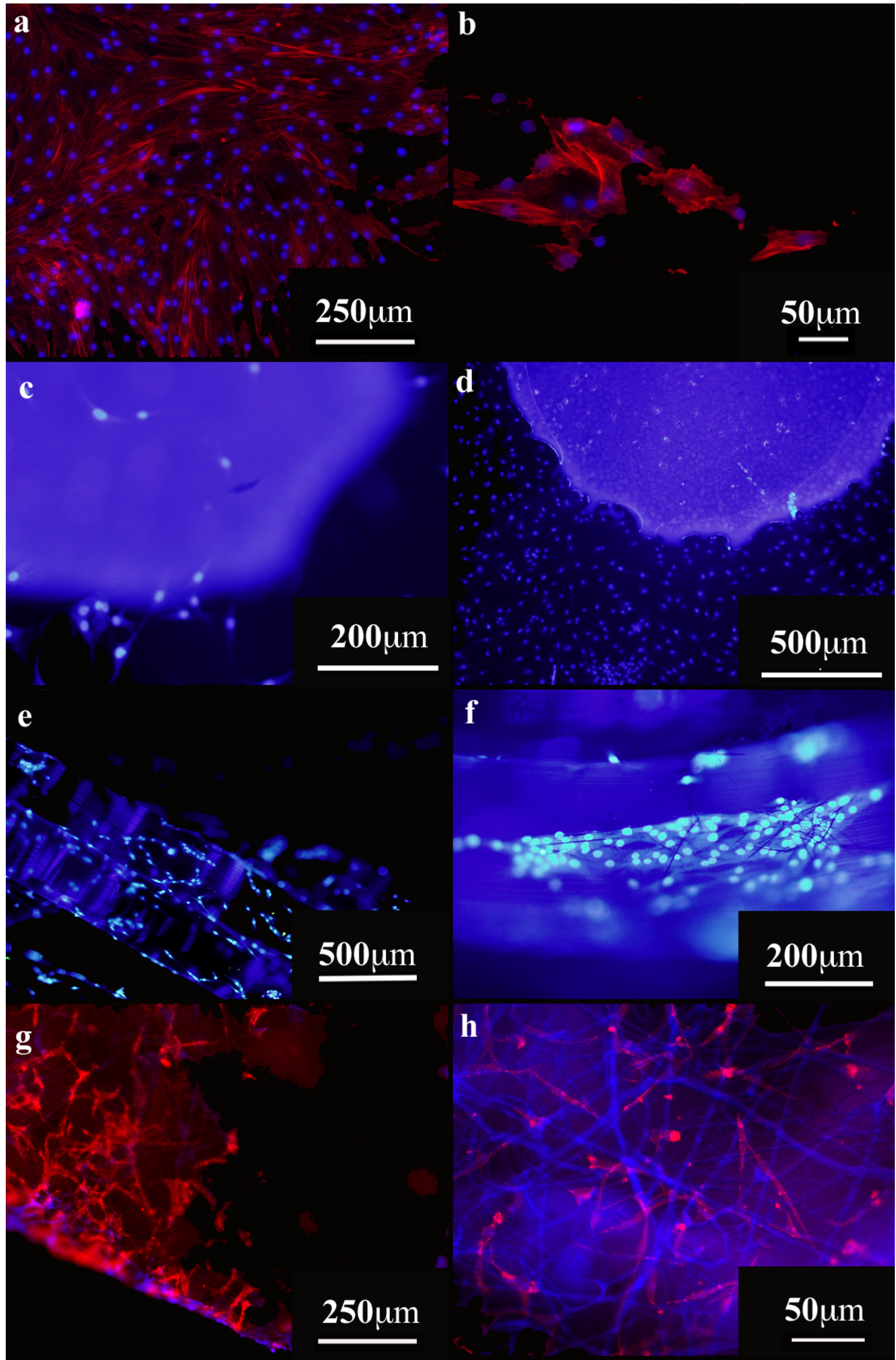

Fig. 8. The appearance of human supraspinatus derived cells attached to plastic (a,b), A polydioxanone “drop" (c,d), Polydioxanone sutures $(\mathbf{e}, \mathbf{f})$ and the electrospun patch $(\mathbf{g}, \mathbf{h})$. Cells were stained with nuclei stain (blue, DAPI) and actin filaments (red, Rhodamine-Phalloidin stain, in images $\mathbf{a}, \mathbf{b}, \mathbf{g}$, and $\mathbf{h}$ ). 
seen in Fig.9, almost $10 \%$ of the cell on the patch could be attracted to migrate across (or around) the patch and the insert's membrane compared to around $20 \%$ of cells migrating directly from the insert membrane.

\section{Simulation of application}

As part of the in vitro assessment of the patch, it was of interest to simulate the implantation of the patch in order to prove that its placement above the repair site, detection by ultrasound and injection of factors into the created confinement were all feasible.

As can be seen in Fig. 10, when the patch was attached to a sample of sheep infraspinatus tendon and embedded within a gelatin-based phantom model in order to simulate the in vivo imaging environment, it was easily detected by ultrasound and the injection needle could be directed into the confinement between the patch and the tendon.

The patch was used to cover a rotator cuff repair in a sheep cadaver (Fig. 11). Following a double row repair with non-absorbable sutures (A), a sheet of the electrospun material was trimmed into an approximately $3 \mathrm{~cm}$ wide patch and stitched to the tendon using PDSII sutures (B). Following that, the complete repair was covered with a muscle flap and using ultrasound (as shown in Fig. 10), two injections of ink were guided to the confinement area directly under the patch. When the flap was re-opened, the localisation of both the green and yellow ink was visible (C), and upon removal of the patch it was confirmed that the confinement area was accurately targeted using the ultrasound-guided injection and that the injected ink was contained within the confinement zone (D).

\section{Discussion}

We presented a set of in vitro preliminary assessments for a novel patch designed to confine and contain beneficial factors for rotator cuff repair. The design of the patch was driven by its surgical function, and the following aspects were especially considered:

1. Good handling characteristics

2. Degradation rate - intact for at least 4-6 weeks

3. Biocompatible (whole patch and degradation products)

4. Able to act as a cell substrata as well as allow cell migration.

The discussion will cover each one of these aspects in relation to the design of the patch and the experimental results presented above.

\section{Handling characteristics}

As described earlier, both PDO foil and sutures (PDSII) have poor handling characteristics and considered stiff and difficult to manipulate. It was thus a priority to produce an implant that surgeons could comfortably handle, especially as many rotator cuff repairs are now performed by arthroscopy (Lorbach and Tompkins, 2012). The electrospinning technique produced a flexible, randomly oriented fibrous mesh that could be cut into the desired dimensions. As demonstrated by our sham operation, the patch could be stitched above a conventional rotator cuff repair, an approach also proposed for re-enforcement with non-degradable patches (Encalada-Diaz et al., 2011).

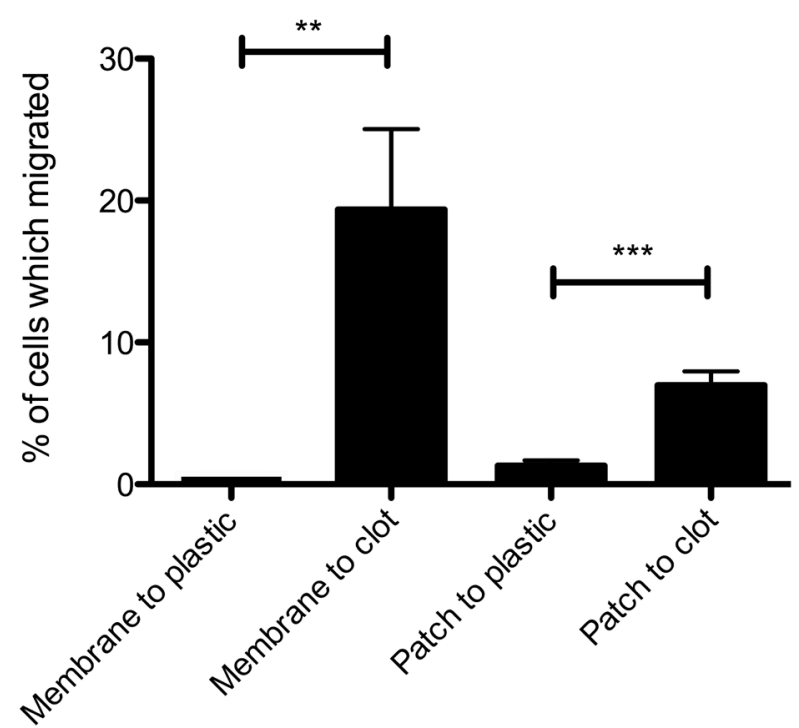

Fig. 9. The percentage of cells that migrated across the $12 \mu \mathrm{m}$ pores in the insert membrane over $48 \mathrm{~h}$. Migration across the membrane was significantly higher in the presence of a fibrin clot.

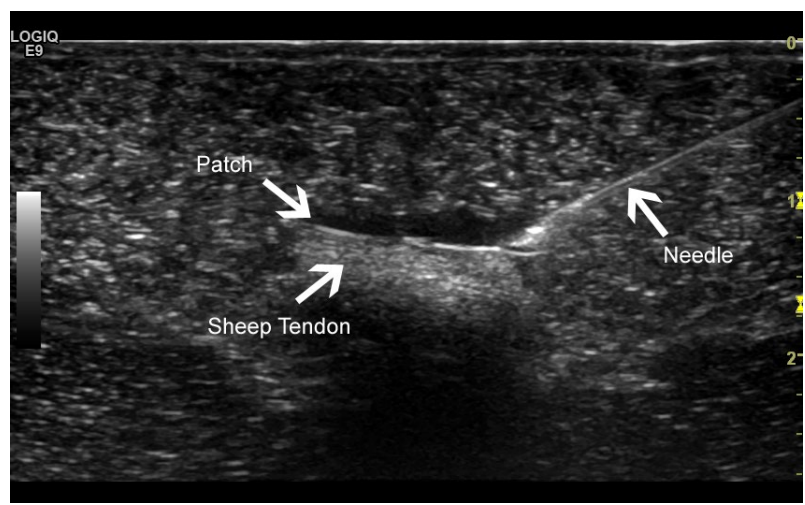

Fig. 10. An ultrasound image, demonstrating the visibility of the electrospun polydioxanone patch adjacent to a sheep tendon. The surgeon could successfully direct the syringe needle to the surface of the patch.

Recent studies have proposed the delivery of growth factor to the tendon to enhance healing by different methods, including soaking scaffolds with growth factors (Raghavan et al., 2012) or coating sutures (Dines et al., 2012). The incorporation of growth factors into electrospun scaffolds has also been suggested (Meinel et al., 2012). However, these delivery methods do not overcome the short half-life of most cytokines, and alternative "stabilising" delivery vehicles are being sought (Raghavan et al., 2012). Here, we propose to overcome this issue by delivering beneficial factors post-operatively into the patch by ultrasound-guided injections. The dense nature of the electrospun mesh, demonstrated by SEM, enabled fluid retention in the confinement zone above the repair, and was detectable by ultrasound, enabling surgeons to revisit the repair sight at later time points.

\section{Degradation rate}

Tendon healing is thought to have similar stages and timeline as most musculoskeletal soft tissues of (a) 

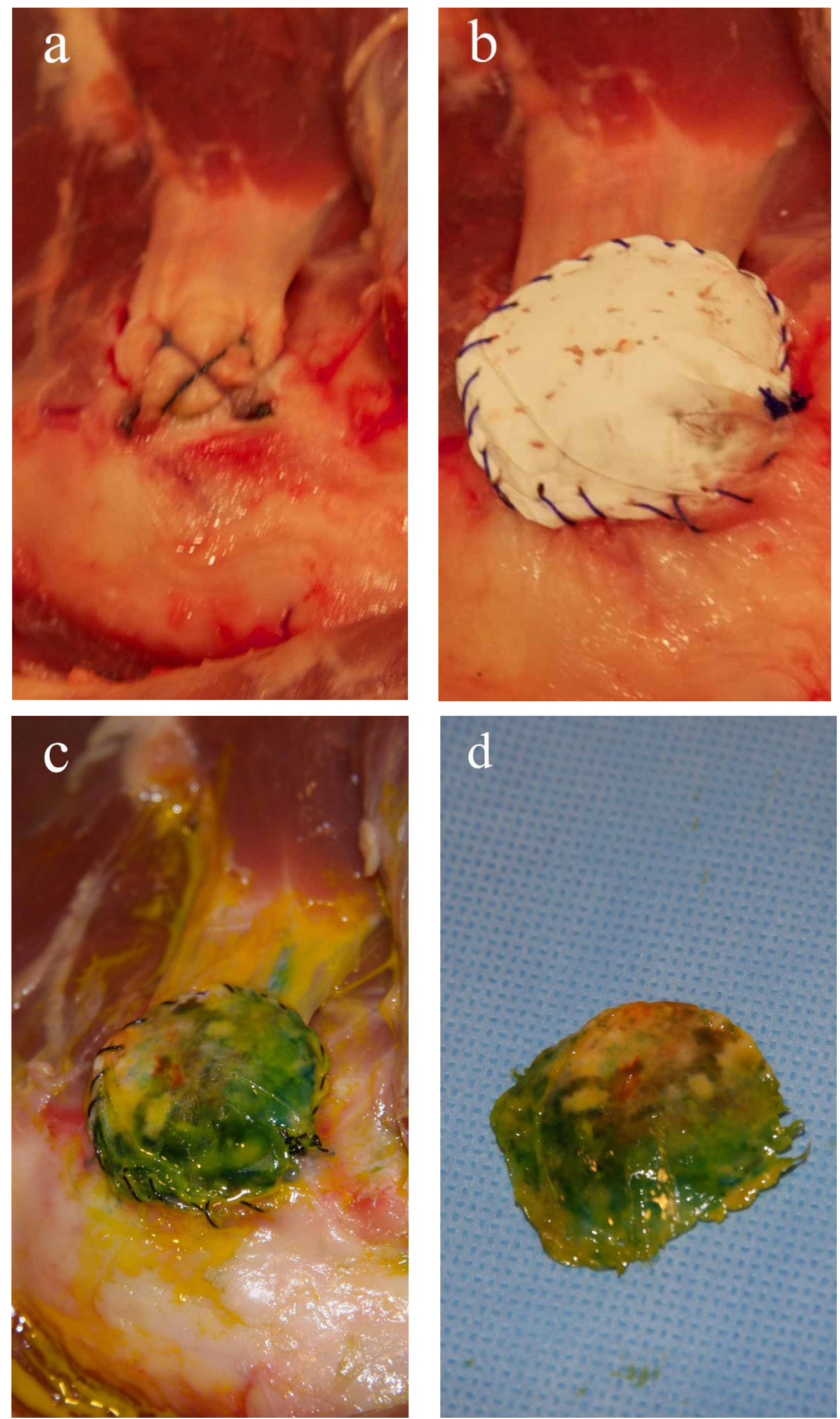

Fig. 11. A sham operation on a sheep shoulder, demonstrating a possible procedure of rotator cuff repair with the electrospun patch. (a) A double row rotator cuff repair using non-degradable Fibrewire Sutures. (b) The patch stitched over the repair, creating a confinement directly above the tear. (c) Following an ultrasound-guided injection, the patch was injected with ink. (d) The patch is removed and the side facing the tendon has absorbed large amounts of ink. 
inflammation, lasting 1-5 days, (b) proliferation/repair/ matrix synthesis, lasting around 1-8 weeks and (c) extracellular matrix (ECM) remodelling, normally starts around 6 weeks after the injury (Walsh, 2006). In order to boost the repair, it would be desirable to stimulate cell activity during the proliferative stage, when fibroblasts divide and synthesise new ECM. Thus, it is desirable that the patch will remain intact for the 4-6 weeks following repair, enabling confinement of injected biological factors such as growth factors. Thereafter, a rapid degradation is desirable in order to minimise inflammation and interference with the remodelling stage. This is a novel approach, as the degradation window for rotator cuff patches is not clearly stated in studies using degradable scaffolds, and materials selected had greatly varying degradation times (Chen et al., 2009; James et al., 2011; Beason et al., 2012).

We carried out a few simple experiments to determine the rate of degradation and compare it to that of PDSII sutures, which take around 120-180 days to completely absorb in vivo (Pillai and Sharma, 2010). The in vitro degradation data presented here showed an accelerated weight loss of the electrospun patch compared to PDSII sutures, with a measurable change in the weight and integrity of patch between week 3 and 6 . These results are in line with previous degradation studies of electrospun PDO-protein blends, moulded PDO/PCL blends and sutures (Im et al., 2007; Thomas et al., 2009; Oh et al., 2011;). SEM images showed that, despite gradual erosion of the patch, much of it remained intact even after 8 weeks of incubation. These results are positive in light of the 'healing window' aimed at weeks 1-4 after the surgery. Polydioxanone degrades by hydrolysis only, with no effect of cellular enzymes (Kulkarni et al., 2008). However, the $\mathrm{pH}$ of the surrounding media has a great impact on the speed of degradation, with acidic environments significantly slowing down degradation (Bird et al., 1991). One limitation of the experiments presented here is that although the patch was suspended in growth medium under physiological conditions, there was no simulation of the dynamic fluid flow in the joint, and therefore some in vivo data will be necessary to validate our approximation.

\section{Biocompatibility}

The degradation products of absorbable implants are critical when evaluating safety and efficacy, particularly as past studies have indicated that implanting large volumes of degradable polymers may cause poor tissue restoration (Bostman et al., 2005). Our results showed that tendon derived cells grew very well on the electrospun patch for up to 21 days, and that the degradation products which leached from the patch over 8 weeks were safe with only a minimal effect by the end of the experiment. Moreover, the degradation products of the commercial product Ethisorb showed a strong inhibitory effect on tendon-derived cells from three weeks of incubation onward. Ethisorb has two components; a porous structure of Vicryl (polyglactin 910) fleece, designed to allow tissue in-growth; and a PDO film coating designed to minimise leakage of cerebrospinal fluid. Absorption of this implant is stated to be complete within 90 days of implantation. The degradation products of Ethisorb are glycolic and lactic (from the polyglactin) and glyoxylic acid (from the polydioxanone component). A comparison of all of these $\alpha$-hydroxy acids showed that they had similar effect on the tendon-derived cell population across a range of concentrations, and that a concentration of $100 \mathrm{mM}$ or above was toxic to the cells. This strongly points to the mechanism and rate of degradation, rather than composition, being critical to the safety of the implant. Similar results have recently been reported for osteoblasts exposed to lactic and glycolic acid, causing decreased cell proliferation, and the authors further suggested this could impede local healing (Meyer et al., 2012).

The side effect of releasing excess acid into the joint should thus be taken into account when designing the patch. In order to cover the repair, we estimate that around 50$100 \mathrm{mg}$ of material will be necessary. The glenohumeral contains a few $\mathrm{mL}$ of synovial fluid, but directly above the repair site there may be only a few hundred $\mu \mathrm{L}$ of fluid. As indicated in Table 1, at a concentration of around $20 \mathrm{mg}$ material in $1 \mathrm{~mL}$ fluid, the maximal concentration of degradation products could reach toxic levels. Thus, a rapidly degrading polymer such as polyglactin 910 will be inappropriate for the confinement patch, whereas a slower degrading polymer such as polydioxanone may be safer. Similar observations have been made in a study of meltmoulded PDO/PCL blend (Oh et al., 2011) as well as our previous study of synthetic degradable sutures (Hakimi et al., 2012). As indicated earlier, in vivo experimentation will be instrumental to confirm this assertion.

\section{Cell attachment and migration}

Among its functions, the patch was expected to act as a cell reservoir, allowing the localised delivery of cells to the repair area. Captured images of tendon-derived cells on the various constructions of PDO presented here clearly showed that the electrospun construction is favourable for cell adhesion and spreading, and that cells could migrate through or around the patch towards a chemo-attractant (fibrin gel). The enhanced cell attachment on the patch compared the sutures is most likely due to the rough surface produced by the electrospinning process. This has been shown to improve cell adhesion compared to smooth surfaces (Lampin et al., 1997; Kim et al., 2007; Gentile et al., 2012). Our results are also in agreement with numerous studies showing excellent cell attachment to electrospun scaffolds (Baker et al., 2006; Sahoo et al., 2006; Hong et al., 2012; Peach et al., 2012), but only a handful focused on PDO (Sell et al., 2006).

This is an important feature of the patch, which could act to retain mesenchymal stem cells above the repair, albeit temporarily. Moreover, good cell migration through the patch is another critical feature, which should allow local fibroblasts to access the covered region of the tendon. Previous studies of electrospun patches have shown that fibre alignment and the addition of biological factors can help orient cell attachment and guide the deposition of collagen fibrils (Moffat et al., 2009; James et al., 2011). Future work will aim to explore such design elements using polydioxanone. 


\section{Limitations}

One major limitation of our study is that the patch is not currently homogenous and varies in thickness and density. To ensure an adequate encapsulation of the repair, it will be necessary to improve the uniformity of the produced material. One possibility to overcome homogeneity issues would be a patterned patch, such as the aligned design previously produced by Boland et al. (Boland et al., 2005).

In our preliminary implantation in the Sheep Phantom model we injected ink into the patch to confirm the accuracy of placement of the injection and the ability of the patch to contain the injected fluid. Further experimentation is required to determine more accurately how different injectables (such as PRP) behave over time with regards to viscosity and mass transport.

Another limitation is the use of primary cells as a test system. This is of limited value, as cell behaviour could greatly vary depending on the patient and explantation process. In this study, we minimised these variations by repeating each study with at least two donors, as well as normalising the data wherever possible. Nevertheless, carrying out in vivo implantation of this scaffold will be necessary to validate the results presented here.

\section{Conclusions}

Electrospun patches have been recently explored for their biological effect on tendon cells. Here, we presented an application-driven study of an electrospun scaffold for rotator cuff repair. This study utilised in vitro tools prior to animal pre-clinical studies in order to ensure the material and its construction are suitable for the outlined application. Electrospun polydioxanone retained the exceptional in vitro biocompatibility reported for polydioxanone sutures, despite its accelerated degradation time. Moreover, it showed improved cell adhesiveness compared to the sutures. There is potential for using this scaffold for numerous applications, particularly to cover the surgical repair of interfaces such as the tendon insertion in the rotator cuff.

\section{Acknowledgments}

The work was supported by the National Institute of Health and Research (NIHR).

\section{References}

Ammon J, Nyland J, Chang H, Burden R, Caborn D (2007) Evaluation of BioCorkscrew and Bioknotless $\mathrm{RC}$ suture anchor rotator cuff repair fixation: an in vitro biomechanical study. Knee Surg Sports Traumatol Arthrosc 15: $1375-1381$.

Audenaert E, Van Nuffel J, Schepens A, Verhelst M, Verdonk R (2006) Reconstruction of massive rotator cuff lesions with a synthetic interposition graft: a prospective study of 41 patients. Knee Surg Sports Traumatol Arthrosc 14: $360-364$.
Awad HA, Butler DL, Boivin GP, Smith FN, Malaviya P, Huibregtse B, Caplan AI (1999) Autologous mesenchymal stem cell-mediated repair of tendon. Tissue Eng 5: 267-277.

Baker SC, Atkin N, Gunning PA, Granville N, Wilson K, Wilson D, Southgate J (2006) Characterisation of electrospun polystyrene scaffolds for three-dimensional in vitro biological studies. Biomaterials 27: 3136-3146.

Baumann A, Burggasser G, Gauss N, Ewers R (2002) Orbital floor reconstruction with an alloplastic resorbable polydioxanone sheet. Int J Oral Maxillofac Surg 31: 367373.

Beason DP, Connizzo BK, Dourte LM, Mauck RL, Soslowsky LJ, Steinberg DR, Bernstein J (2012) Fiberaligned polymer scaffolds for rotator cuff repair in a rat model. J Shoulder Elbow Surg 21: 245-250.

Benson RT, McDonnell SM, Rees JL, Athanasou NA, Carr AJ (2009) The morphological and immunocytochemical features of impingement syndrome and partial-thickness rotator-cuff tear in relation to outcome after subacromial decompression. J Bone Joint Surg 91: 119-123.

Bird IN, Silver IA, Gorham SD, French DA (1991) In vivo degradation of collagen-vicryl materials in rabbit ear chambers. J Mater Sci: Mater Med 2: 36-42.

Bishop J, Klepps S, Lo IK, Bird J, Gladstone JN, Flatow EL (2006) Cuff integrity after arthroscopic versus open rotator cuff repair: a prospective study. J Shoulder Elbow Surg 15: 290-299.

Boland ED, Coleman BD, Barnes CP, Simpson DG, Wnek GE, Bowlin GL (2005) Electrospinning polydioxanone for biomedical applications. Acta Biomater 1: 115-123.

Bongers PM (2001) The cost of shoulder pain at work. BMJ 322: 64-65.

Bostman OM, Laitinen OM, Tynninen O, Salminen ST, Pihlajamaki HK (2005) Tissue restoration after resorption of polyglycolide and poly-laevo-lactic acid screws. J Bone Joint Surg 87: 1575-1580.

Butler DL, Juncosa-Melvin N, Boivin GP, Galloway MT, Shearn JT, Gooch C, Awad H (2008) Functional tissue engineering for tendon repair: A multidisciplinary strategy using mesenchymal stem cells, bioscaffolds, and mechanical stimulation. J Orthop Res 26: 1-9.

Chen J, Xu J, Wang A, Zheng M (2009) Scaffolds for tendon and ligament repair: review of the efficacy of commercial products. Expert Rev Med Devices 6: 61-73.

Chong AKS, Ang AD, Goh JCH, Hui JHP, Lim AYT, Lee EH, Lim BH (2007) Bone marrow-derived mesenchymal stem cells influence early tendon-healing in a rabbit Achilles tendon model. J Bone Joint Surg Am 89: 74-81.

Cole AS, Cordiner-Lawrie S, Carr AJ, Athanasou NA (2001) Localised deposition of amyloid in tears of the rotator cuff. J Bone Joint Surg 83: 561-564.

Costa MA, Wu C, Pham BV, Chong AKS, Pham HM, Chang J (2006) Tissue engineering of flexor tendons: Optimization of tenocyte proliferation using growth factor supplementation. Tissue Eng 12: 1937-1943.

Cummins CA, Murrell GAC (2003) Mode of failure for rotator cuff repair with suture anchors identified at revision surgery. J Shoulder Elbow Surg 12: 128-133. 
Curtis AS, Wilkinson CD, Crossan J, Broadley C, Darmani H, Johal KK, Jorgensen H, Monaghan W (2005) An in vivo microfabricated scaffold for tendon repair. Eur Cell Mater 9: 50-57.

Cushnie EK, Khan YM, Laurencin CT (2010) Tissueengineered matrices as functional delivery systems: Adsorption and release of bioactive proteins from degradable composite scaffolds. J Biomed Mater Res Part A 94A: 568-575.

De Mos M, van der Windt AE, Jahr H, van Schie HT, Weinans H, Verhaar JA, Van Osch GJ (2008) Can plateletrich plasma enhance tendon repair? A cell culture study. Am J Sports Med 36: 1171-1178.

Derwin KA, Baker AR, Spragg RK, Leigh DR, Iannotti JP (2006) Commercial extracellular matrix scaffolds for rotator cuff tendon repair. Biomechanical, biochemical, and cellular properties. J Bone Joint Surg Am 88: 2665-2672.

Derwin KA, Codsi MJ, Milks RA, Baker AR, McCarron JA, Iannotti JP (2009) Rotator cuff repair augmentation in a canine model with use of a woven poly-L-lactide device. J Bone Joint Surg Am 91: 1159-1171.

Derwin K, Baker AR, Iannotti J, McCarron JA (2010) Pre-clinical models for translating regenerative medicine therapies for rotator cuff repair. Tissue Eng Part B Rev 16: 21-30.

Dines JS, Cross MB, Dines D, Pantazopoulos C, Kim HJ, Razzano P, Grande D (2012) In vitro analysis of an rhGDF-5 suture coating process and the effects of rhGDF-5 on rat tendon fibroblasts. Growth Factors 29: 1-7.

Encalada-Diaz I, Cole BJ, MacGillivray JD, RuizSuarez M, Kercher JS, Friel NA, Valero-Gonzalez F (2011) Rotator cuff repair augmentation using a novel polycarbonate polyurethane patch: preliminary results at 12 months' follow-up. J Shoulder Elbow Surg 20: 788-794.

Fang Q, Chen D, Yang Z, Li M (2009) In vitro and in vivo research on using Antheraea pernyi silk fibroin as tissue engineering tendon scaffolds. Mater Sci Eng C 29: 1527-1534.

Fini M, Torricelli P, Giavaresi G, Rotini R, Castagna A, Giardino R (2007) In vitro study comparing two collageneous membranes in view of their clinical application for rotator cuff tendon regeneration. J Orthop Res 25: 98-107.

Galatz LM, Ball CM, Teefey SA, Middleton WD, Yamaguchi K (2004) The outcome and repair integrity of completely arthroscopically repaired large and massive rotator cuff tears. J Bone Joint Surg Am 86-A: 219-224.

Gentile F, Tirinato L, Battista E, Causa F, Liberale C, di Fabrizio EM, Decuzzi P (2012) Cells preferentially grow on rough substrates. Biomaterials 31: 7205-7212.

Hakimi O, Chaudhury S, Murphy R, Carr A (2012) Differential growth on sutures of tendon cells derived from torn human rotator cuff. J Biomed Mater Res B Appl Biomater 100: 685-692.

Hamada Y, Katoh S, Hibino N, Kosaka H, Hamada D, Yasui N (2006) Effects of monofilament nylon coated with basic fibroblast growth factor on endogenous intrasynovial flexor tendon healing. J. Hand Surg-Am 31A: 530-540.

Hong Y, Takanari K, Amoroso NJ, Hashizume R, Brennan-Pierce EP, Freund JM, Badylak SF, Wagner WR (2012) An elastomeric patch electrospun from a blended solution of dermal extracellular matrix and biodegradable polyurethane for rat abdominal wall repair. Tissue Eng Part C Meth 18: 122-132.

Huijsmans PE, Pritchard MP, Berghs BM, van Rooyen KS, Wallace AL, de Beer JF (2007) Arthroscopic rotator cuff repair with double-row fixation. J Bone Joint Surg Am 89: 1248-1257.

Im JN, Kim JK, Kim HK, In CH, Lee KY, Park WH (2007) In vitro and in vivo degradation behaviors of synthetic absorbable bicomponent monofilament suture prepared with poly(p-dioxanone) and its copolymer. Polym Degrad Stabil 92: 667-674.

James R, Kumbar SG, Laurencin CT, Balian G, Chhabra AB (2011) Tendon tissue engineering: adiposederived stem cell and GDF-5 mediated regeneration using electrospun matrix systems. Biomed Mater 6: 025011.

Kajikawa Y, Morihara T, Sakamoto H, Matsuda K, Oshima Y, Yoshida A, Nagae M, Arai Y, Kawata M, Kubo T (2008) Platelet-rich plasma enhances the initial mobilization of circulation-derived cells for tendon healing. J Cell Physiol 215: 837-845.

Kalfa D, Bel A, Chen-Tournoux A, Della Martina A, Rochereau P, Coz C, Bellamy V, Bensalah M, Vanneaux V, Lecourt S, Mousseaux E, Bruneval P, Larghero J, MenaschÈ P (2010) A polydioxanone electrospun valved patch to replace the right ventricular outflow tract in a growing lamb model. Biomaterials 31: 4056-4063.

Kim MS, Shin YN, Cho MH, Kim SH, Kim SK, Cho YH, Khang G, Lee IW, Lee HB (2007) Adhesion behavior of human bone marrow stromal cells on differentially wettable polymer surfaces. Tissue Eng 13: 2095-2103.

Kimura A, Aoki M, Fukushima S, Ishii S, Yamakoshi K (2003) Reconstruction of a defect of the rotator cuff with polytetrafluoroethylene felt graft. Recovery of tensile strength and histocompatibility in an animal model. J Bone Joint Surg 85: 282-287.

Kontio R, Ruuttila P, Lindroos L, Suuronen R, Salo A, Lindqvist C, Virtanen I, Konttinen YT (2005) Biodegradable polydioxanone and poly $(1 / \mathrm{d})$ lactide implants: an experimental study on peri-implant tissue response. Int J Oral Maxillofac Surg 34: 766-776.

Kulkarni A, Reiche J, Hartmann J, Kratz K, Lendlein A (2008) Selective enzymatic degradation of poly(epsiloncaprolactone) containing multiblock copolymers. Eur J Pharm Biopharm 68: 46-56.

Lampin M, Warocquier C, Legris C, Degrange M, Sigot-Luizard MF (1997) Correlation between substratum roughness and wettability, cell adhesion, and cell migration. J Biomed Mater Res 36: 99-108.

Lorbach O, Tompkins M (2012) Rotator cuff: biology and current arthroscopic techniques. Knee Surg Sports Traumatol Arthrosc 20: 1003-1011.

Maniscalco P, Gambera D, Lunati A, Vox G, Fossombroni V, Beretta R, Crainz E (2008) The "Cascade" membrane: a new PRP device for tendon ruptures. Description and case report on rotator cuff tendon. Acta Biomed 79: 223-226.

Martin C, Winet H, Bao JY (1996) Acidity near eroding polylactide-polyglycolide in vitro and in vivo in rabbit tibial bone chambers. Biomaterials 17: 2373-2380. 
McCarrel T, Fortier L (2009) Temporal growth factor release from platelet-rich plasma, trehalose lyophilized platelets, and bone marrow aspirate and their effect on tendon and ligament gene expression. J Orthop Res 27: 1033-1042.

Meinel AJ, Germershaus O, Luhmann T, Merkle HP, Meinel L (2012) Electrospun matrices for localized drug delivery: Current technologies and selected biomedical applications. Eur J Pharm Biopharm 81: 1-13.

Meyer F, Wardale J, Best S, Cameron R, Rushton N, Brooks R (2012) Effects of lactic acid and glycolic acid on human osteoblasts: A way to understand PLGA involvement in PLGA/calcium phosphate composite failure. J Orthopaed Res 30: 864-871.

Mikos AG, McIntire LV, Anderson JM, Babensee JE (1998) Host response to tissue engineered devices. Adv Drug Deliv Rev 33: 111-139.

Moffat KL, Kwei AS, Spalazzi JP, Doty SB, Levine WN, Lu HH (2009) Novel nanofiber-based scaffold for rotator cuff repair and augmentation. Tissue Eng Part A 15: 115-126.

Muller M, Appleyard R, Osbahr DC, Murrell GAC (2003) Meshes in rotator cuff repair: A biomechanical study. Techn Shoulder Elbow Surg 4: 50-54.

Oh SH, Park SC, Kim HK, Koh YJ, Lee JH, Lee MC, Lee JH (2011) Degradation behavior of 3D porous polydioxanone-b-polycaprolactone scaffolds fabricated using the melt-molding particulate-leaching method. J. Biomater Sci-Polym Ed 22: 225-237.

Peach MS, James R, Toti US, Meng D, Morozowich NL, Allcock HR, Laurencin CT, Kumbar SG (2012) Polyphosphazene functionalized polyester fiber matrices for tendon tissue engineering: in vitro evaluation with human mesenchymal stem cells. Biomed Mater 7: 045016.

Pillai CKS, Sharma CP (2010) Review Paper: Absorbable polymeric surgical sutures: Chemistry, production, properties, biodegradability, and performance. J Biomater Appl 25: 291-366.

Poulsen RC, Carr AJ, Hulley PA (2011) Protection against glucocorticoid-induced damage in human tenocytes by modulation of ERK, Akt, and forkhead signaling. Endocrinology 152: 503-514.

Raghavan SS, Woon CYL, Kraus A, Megerle K, Pham H, Chang J (2012) Optimization of human tendon tissue engineering: Synergistic effects of growth factors for use in tendon scaffold repopulation. Plast Reconstr Surg 129: 479-489.

Rodeo SA (2007) Biologic augmentation of rotator cuff tendon repair. J Shoulder Elbow Surg 16: S191-S197.

Rohrich RJ, Trott SA, Love M, Beran SJ, Orenstein HH (1999) Mersilene suture as a vehicle for delivery of growth factors in tendon repair. Plast Reconstr Surg 104: 1713-1717.

Sahoo S, Ouyang H, Goh JC, Tay TE, Toh SL (2006) Characterization of a novel polymeric scaffold for potential application in tendon/ligament tissue engineering. Tissue Eng 12: 91-99.

Sell SA, McClure MJ, Barnes CP, Knapp DC, Walpoth BH, Simpson DG, Bowlin GL (2006) Electrospun polydioxanone-elastin blends: potential for bioresorbable vascular grafts. Biomed Mater 1: 72-80.
Shea KP, Obopilwe E, Sperling JW, Iannotti JP (2012) A biomechanical analysis of gap formation and failure mechanics of a xenograft-reinforced rotator cuff repair in a cadaveric model. J Shoulder Elbow Surg 21: 1072-1079.

Silva A, Sampaio R (2009) Anatomic ACL reconstruction: does the platelet-rich plasma accelerate tendon healing? Knee Surg Sports Traumatol Arthrosc 17: 676-682.

Sugaya H, Maeda K, Matsuki K, Moriishi J (2007) Repair integrity and functional outcome after arthroscopic double-row rotator cuff repair - A prospective outcome study. J Bone Joint Surg-Am 89A: 953-960.

Thomas V, Zhang X, Vohra YK (2009) A biomimetic tubular scaffold with spatially designed nanofibers of protein/PDS bio-blends. Biotechnol Bioeng 104: 10251033.

Tweedie DJ, Lo S, Rowe-Jones JM (2010) Reconstruction of the nasal septum using perforated and unperforated polydioxanone foil. Arch Facial Plastic Surg 12: 106-113.

Urwin M, Symmons D, Allison T, Brammah T, Busby H, Roxby M, Simmons A, Williams G (1998) Estimating the burden of musculoskeletal disorders in the community: the comparative prevalence of symptoms at different anatomical sites, and the relation to social deprivation. Ann Rheum Dis 57: 649-655.

Walsh WR (2006) Repair and Regeneration of Ligaments, Tendons, and Joint Capsule. Humana Press, Totowa, New Jersey.

Yao L, Bestwick CS, Bestwick LA, Maffulli N, Aspden RM (2006) Phenotypic drift in human tenocyte culture. Tissue Eng 12: 1843-1849.

\section{Discussion with Reviewer}

Reviewer I. As future reference: what animal model would the authors use to test the patch in vivo? Can you explain briefly the experimental design?

Authors: We are currently considering rabbit. rat and mouse models to test the biocompatibility and safety of our patch. These are well established and cheap. Whilst a larger animal model may help to shed more light on the efficacy of the patch, there isn't a gold standard model for such experiments, and they are expensive and labour intensive. We are keenly following the work of Dr Derwin (Derwin et al., 2009) who is currently investigating larger animal models.

Reviewer I: What will give better results: loading the patch via injections with PRP or soluble growth factors only? Why?

Authors: We believe both routes should be explored, mainly because previous clinical studies of PRP as a therapeutic for tendon repair did not consider a method to retain the PRP around the repair. It is highly speculative, but as PRP has evolved to encourage healing, cell recruitment and scar tissue formation, it appears less likely that a single growth factor or a prepared growth factor cocktail could be as effective. However, this remains to be tested in future trials. 